\title{
Effects of processing whole oats on the analysis and fate of mycotoxins and
} ergosterol

\author{
S.A. Tittlemier", R. Blagden, J. Chan, T.L. McMillan, K. Pleskach and M.S. Izydorczyk \\ Grain Research Laboratory, Canadian Grain Commission, 1404-303 Main St., Winnipeg, Manitoba R3C 3G8, Canada; \\ sheryl.tittlemier@grainscanada.gc.ca
}

Received: 4 October 2019 / Accepted: 15 November 2019

(๑) 2020 Wageningen Academic Publishers

OPEN ACCESS CC) (1) () () RESEARCH ARTICLE

\begin{abstract}
Grinding and dividing equipment were evaluated for their ability to comminute and divide ground oats in preparation for mycotoxin analysis. Four different grinders, using various settings, were evaluated for their ability to comminute oats and produce small particle sizes. Rotor beater type grinders produced the more desirable finer ground samples as compared to burr type mills. Four different division methods (manual scooping, rotary sample division, and two designs of gravity-fed dividers) were assessed for their ability to produce sub-samples with consistent particle size fraction distributions. No practical differences were observed on the particle size fraction distribution of test portions of finely ground oats produced using the four different division methods; therefore, no effects on mycotoxin analysis were anticipated. The effects of processing naturally contaminated whole oats on mycotoxin concentrations was also assessed. Laboratory scale dehulling, steaming, and kilning were examined. Dehulling showed the greatest impact and removed $60-100 \%$ of various Fusarium- and Alternaria-produced mycotoxins, as well as ergosterol, present on the naturally contaminated whole oats. Different from the other analytes studied, only $48 \%$ of the mycotoxin plant transformation product deoxynivalenol-3-glucoside was present in hulls and removed during dehulling. Steaming and kilning appeared to increase ergosterol in groats, as well as decrease deoxynivalenol and deoxynivalenol-3glucoside. The observed inconsistent changes in concentrations of tentoxin after heat treatment of groats appeared to be due to sample heterogeneity.
\end{abstract}

Keywords: sampling, grinding, dehulling, heat, deoxynivalenol, ochratoxin A, deoxynivalenol-3-glucoside

\section{Introduction}

Oats (Avena sativa) are grown for food and feed uses. The three main markets for oats are milling, feed for livestock, and performance feed for horses (Bouphasiri and Verchomin, 2005). Due to the presence of an outer hull on the oat kernel, and relatively high lipid content compared to other cereals, various steps are required to process raw whole oats (i.e. oats with hull and other kernel components still intact and together) into consumable food and feed products. These steps can include physically removing the outer hull to produce groats, heat treatment to inactivate lipase enzymes and prevent rancidity, and flaking or milling. The specific processes used is guided by the ultimate use of the oats as food or feed. A good introduction to the various processes involved in oat milling and processing for use in food products is presented by Scudamore et al. (2007).

As a cereal, oats are susceptible to fungal infection in both their growing and storage environments. Fungal infection can result in the accumulation of mycotoxins in the kernel, which leads to the exposure of food and feed consumers to these potentially hazardous compounds. Many studies have reported on the occurrence of mycotoxins in Canadian oats, and some have noted that the frequency and level of occurrence in oats is lower than for other cereal grains (Campbell et al., 2002; Martos et al., 2010). The Fusariumproduced deoxynivalenol (DON), HT-2 and T-2 toxins, as well as Penicillium avenaceum-produced ochratoxin A (OTA) have been measured in Canadian oats (Clear et al., 2000; Tamburic-Ilincic, 2010; Tittlemier et al., 2020; 
Whitaker et al., 2015a; Yan et al., 2017). The less studied Fusarium-produced culmorin, enniatins, and beauvericin, as well as Alternaria mycotoxins, have also been observed in Canadian oats (Tittlemier et al., 2020).

Due to the potentially heterogeneous nature of mycotoxins in cereal grains, analysis of grains for mycotoxins can be challenging. This is particularly the case for the analysis of OTA (Tittlemier et al., 2011), and other mycotoxins that are associated with point sources in bulk grain, such as ergot alkaloids. As awareness of the importance of proper sampling and sample preparation is increasing, only a small number of studies have investigated the effects of sample preparation processes on the analysis of mycotoxins in grains (Grusie et al., 2017; Tittlemier et al., 2012). These studies examined the effect of sample size on variability of results, the distribution of mycotoxins amongst various particle sizes of comminuted grain, and the effect of particle size distribution of comminuted grain on measured concentrations. Neither of these studies included oats as a matrix.

Other studies have examined the fate of mycotoxins in oats undergoing various processing. Scudamore et al. (2007) studied the fate of DON, HT-2, and T-2 and other Fusarium-produced mycotoxins and derivatives in oats processed in a commercial mill in the United Kingdom. Ivanova et al. (2016) studied the fate of a wide variety of mycotoxins in Norwegian oats subjected to removal of the outer hull and subsequent abrasion of outer layers of the remaining groats. The effects of extrusion cooking on OTA (Lee et al., 2017) and HT-2 and T-2 (Schmidt et al., 2017), as well as the effects of making biscuits and muesli have also been studied (Kuchenbuch et al., 2018). In general, significant decreases in mycotoxin contents were observed after dehulling, with some decreases after processing involving high heat as well. The degree of change in concentration varied with mycotoxin identity, as well as the specific processing conditions used. These have all focused on the fate of mycotoxins as oats are processed for food, and did not touch upon processing of oat samples for laboratory analysis.

There were four main objectives of the current research. The first was to compare the performance of different equipment when grinding whole oats by assessing the particle size distributions produced. The second was to compare the performance of different equipment when dividing ground oats by assessing the consistency of the particle size distribution produced. The third objective was to determine if mycotoxins and the fungal biomarker ergosterol (Seitz et al., 1977) are associated with particular particle size fractions in order to help guide sampling and processing procedures to ensure representative samples are prepared for analysis. The final objective was to investigate if dehulling and heat treatment of oats affects mycotoxin and ergosterol concentrations. This final objective will determine how mycotoxin concentrations are affected by processing and will help regulators develop accurate exposure assessments for consumers of oats.

\section{Materials and methods}

\section{Comparison of grinders for the comminution of whole oats}

The ability of four different grinders to comminute whole oats (i.e. oats with intact hulls) was assessed. The four grinders used were (1) a commercial coffee grinder (model KR 804, Ditting Maschinen AG, Bachenbülach, Switzerland); (2) the Romer Series II sub-sampling mill (Romer Labs, Union, MO, USA); (3) a Retsch SR 300 rotor beater mill coupled with a Retsch DR 100 vibratory feeder (Retsch, Haan, Germany); and (4) a Perten 3100 hammer mill (Perten instruments, Hägersten, Sweden).

Nine scenarios were used to grind $1 \mathrm{~kg}$ of whole oats (Table 1); oats used were representative of the quality exported for further processing. The scenarios incorporated different settings on the four grinders and were used to obtain various particle size distributions. The time taken to grind the oats and clean the grinder (including disassembly if required) to prepare for grinding a subsequent sample was recorded for each scenario by the laboratory personnel.

\section{Analysis of particle size distribution of ground oats}

Ground oats were sub-sampled using a rotary sample divider (Materials Sampling Solutions, Southport, Australia) with vibratory feeder (HI-VI models 15A and D20N; Eriez Manufacturing Co., Erie, PA, USA) to obtain a $100 \mathrm{~g}$ test portion of ground oats. The vibratory feeder amplitude was set to $50 \%$ and the carousel containing the 10 collection containers rotated at a constant speed of $12 \mathrm{rpm}$.

\section{Table 1. Comparison of grinders and settings when grinding $1 \mathrm{~kg}$ of whole oats.}

\begin{tabular}{lll} 
Grinder & Setting' & Time (min) \\
Ditting & coarse ('French Press') & 5 \\
Ditting & fine ('Turkish grind') & 7 \\
Romer & coarse (dial setting '1') & 31 \\
Romer & fine (dial setting '5') & 37 \\
Retsch & $1000 \mu \mathrm{m}$ & 5 \\
Retsch & $750 \mu \mathrm{m}$ & 5 \\
Retsch & $500 \mu \mathrm{m}$ & 6 \\
Perten & $800 \mu \mathrm{m}$ & 31 \\
Perten & $500 \mu \mathrm{m}$ & 37 \\
\hline \multirow{2}{*}{ Values refer to the nominal size of the openings on the sieve used in } \\
\multicolumn{2}{l}{ each scenario. } &
\end{tabular}


The particle size distribution of the ground oats produced by each grinding scenario was determined using a laboratoryscale plansifter. The particle size distribution was measured by mechanically sifting (at $220 \mathrm{rpm}$ ) the test portion through a rotary plansifter comprised of a series of vertically stacked sieves $(0.33 \times 0.33 \mathrm{~m})$ with nylon mesh screens of various sized openings $(1,180 \mu \mathrm{m}, 475 \mu \mathrm{m}, 300 \mu \mathrm{m}, 180 \mu \mathrm{m}$, and $110 \mu \mathrm{m})$. After $10 \mathrm{~s}$ of sifting, the material remaining on top of the $1180 \mu \mathrm{m}$ was collected. Material remaining on top of each of the four remaining sieves was collected after successive $5 \mathrm{~s}$ periods of sifting. Material smaller than $110 \mu \mathrm{m}$ was collected from the bottom pan. All sifting was performed with no tapping of the sieves in order to maximise consistency of analysis amongst samples. Losses were calculated as the difference between the initial test portion mass and the total mass of collected fractions. Six particle size fractions were collected: $>1,180 \mu \mathrm{m},>475$ to $1,180 \mu \mathrm{m},>300$ to $475 \mu \mathrm{m},>180$ to $300 \mu \mathrm{m},>110$ to $180 \mu \mathrm{m}$, and $<110 \mu \mathrm{m}$. The masses of the 6 particle size fractions were determined using a top loading balance (MS3002S; Mettler Toledo, Columbus, OH, USA).

\section{Comparison of division methods for ground oats}

Whole oats were ground and divided into three replicate test portions of approximately $100 \mathrm{~g}$ using four different dividing methods. Two different grinding scenarios that covered desirable and undesirable particle size fraction distributions were used to produce ground oats. To produce the desirable particle size fraction distribution (i.e. containing more of the smaller particles), $4 \times 1 \mathrm{~kg}$ of whole oats were ground using the Retsch mill fitted with a $500 \mu \mathrm{m}$ sieve. For the undesirable particle size fraction distribution, $4 \times 1 \mathrm{~kg}$ of whole oats were ground using the commercial coffee grinder on the coarsest setting. Then $1 \mathrm{~kg}$ portions of ground oats from the desirable and undesirable grinding scenarios were each divided using four different methods.

In the first method, $1 \mathrm{~kg}$ of ground oats was divided using a riffle divider with 14 alternating channels that moved sample into two directions (H-3966, Humboldt Testing Equipment, Norridge, IL, USA). The riffle divider split samples into two portions. With this equipment, $1 \mathrm{~kg}$ of ground oats was placed in a pan whose length was equal to the width of the riffle divider hopper. The pan was tipped over in one motion and two fractions were collected in separate pans whose whole length was equal to the width of the riffle divider hopper. After the first halving of the $1 \mathrm{~kg}$ of ground oats, both fractions were recombined and split again. Then one half was selected and divided in multiple iterations using the riffle divider to prepare test portions of approximately $100 \mathrm{~g}$.

In the second method, manual scooping using a metal scoop was used to prepare approximately $100 \mathrm{~g}$ test portions. The $1 \mathrm{~kg}$ was sampling by taking 10 scoops. Initially 5 scoops were taken from different locations in the sample container. Remaining sample was mixed by shaking for approximately $30 \mathrm{~s}$ and then the remaining 5 scoops were taken from different locations of the container.

For the third division method, a Boerner divider (Seedburo Equipment Company, Des Plaines, IL, USA) was used. Ground oats $(1 \mathrm{~kg})$ were placed in the hopper with the spout valve closed. After all samples were added, the valve was opened and two separate pans were used to collect the two fractions produced. After the first halving of the $1 \mathrm{~kg}$ of ground oats, both fractions were recombined and split again. Then one half was selected and divided in multiple iterations on the Boerner divider to prepare test portions of approximately $100 \mathrm{~g}$.

For the last method, the rotary sample divider and process described in 'Analysis of particle size distribution of ground oats' was used. The $1 \mathrm{~kg}$ sample of ground oats was passed through the rotary sample divider twice. On the second pass, the 10 individual $100 \mathrm{~g}$ portions were collected.

The particle size distribution of the ground oats produced by the various dividing methods was determined using mechanical sifting as described above. Three approximately $100 \mathrm{~g}$ test portions from each of the four dividing methods were analysed. The division methods for the ground oats were evaluated by considering the mean and standard deviation $(n=3)$ of the percentage of the total sample mass for each particle size fraction obtained from box sifting.

\section{Distribution of mycotoxins and ergosterol amongst particle size fractions}

Two samples of oats (2 $\mathrm{kg}$ each), portions of which were previously analysed and found to contain a number of mycotoxins, were ground using the Retsch mill fitted with the $500 \mu \mathrm{m}$ sieve. The ground samples were sifted through a laboratory-scale plansifter described above. The ground samples (one $100 \mathrm{~g}$ portion from each sample) were placed on the top sieve and sifted for $90 \mathrm{~s}$. The top sieve was tapped 3 times on each side with a rubber hammer. After tapping, the material remaining on the top sieve $(1,180 \mu \mathrm{m})$ was collected. Material remaining on top of each of the remaining sieves was collected after successive $90 \mathrm{~s}$ periods of sifting and tapping. Material smaller than 110 $\mu \mathrm{m}$ was collected by brushing down the last sieve $(110 \mu \mathrm{m})$ into the bottom pan. The collected particle size fractions were analysed for mycotoxins and ergosterol. Ultrahigh performance liquid chromatography with tandem mass spectrometry (LC-MS/MS) was used to analyse for DON, deoxynivalenol-3-glucoside (DON-3G), 15-acetyl deoxynivalenol (15-ADON), 3-acetyl deoxynivalenol (3-ADON), culmorin (CUL), zearalenone (ZEN), HT-2 toxin, T-2 toxin, nivalenol (NIV), beauvericin (BEA), enniatin A (ENN A), enniatin A1 (ENN A1), enniatin B 
(ENN B), enniatin B1 (ENN B1), fumonisin $B_{1}$, fumonisin $\mathrm{B}_{2}$, alternariol $(\mathrm{AOH})$, alternariol methyl ether (AME), altenuene (ALT), tentoxin (TTX), ochratoxin A (OTA), citrinin, aflatoxin $B_{1}$, aflatoxin $B_{2}$, aflatoxin $G_{1}$, and aflatoxin $\mathrm{G}_{2}$. The method was performed as described in Tittlemier et al. (2019).

Briefly, samples were extracted with acetonitrile/water/ acetic acid and diluted in mobile phase. Stable isotopelabelled ${ }^{13} \mathrm{C}$ internal standards were added to the diluted sample extract prior to instrumental analysis. Mass spectrometric analysis was performed using electrospray ionisation with polarity switching. Two transitions were monitored and used to identify and quantify each of the mycotoxin analytes. Mycotoxins were quantified using a calibration curve constructed from 7 external standards. Peak areas from quantitation transitions were normalised to the peak area of ${ }^{13} \mathrm{C}$-labelled internal standard during data analysis in order to mitigate matrix effects on quantitation prior to interpolation of analyte concentration from the calibration curve.

Analytes were considered to be identified and were quantified when their retention time was within $0.1 \mathrm{~min}$ of the mean retention time in external standards, the ratio of qualifier to quantitation transition was within $\pm 30 \%$ of the mean ratio in external standards, and the peak area signal-to-noise ratio was at least 10:1. Gas chromatography with mass spectrometry (GC-MS) was used to analyse samples for ergosterol as described in Tittlemier et al. (2019) and based on Chen et al. (2016). Ground oats were extracted with $10 \% \mathrm{KOH}$ in methanol, and further extracted with hexane. The hexane layer was taken to dryness and ergosterol was derivatised with a solution of N-trimethylsilylimidazole: trimethylchlorosilane. The trimethylsilyl derivative of ergosterol was quantitated using matrix-matched calibration standards after analysis by GC-MS in electron impact mode.

\section{Effect of dehulling, steaming, and kilning oats on mycotoxin and ergosterol concentrations}

Whole oats (14 samples, 1,500 g each) were dehulled using a laboratory-scale huller (LH-5095, Codema, Maple Grove, MN, USA). Whole oats were processed in the huller for $55 \mathrm{~s}$ in batches until the entire $1500 \mathrm{~g}$ were completed. After dehulling, the groats were passed through a dockage tester (Carter Day International, Minneapolis, MN, USA) to remove any remaining hulls. Groats and remainders (oat kernels that were not dehulled) were passed through the laboratory-scale huller and dockage tester for a second time. Remainders were manually removed from the groats. Groats, remainders, and hulls were collected, weighed, and stored separately for each oat sample.
A rotary sample divider was used to split groats into two equally sized portions. One portion was used for mycotoxin analysis, and the other was subjected to heat treatment. Groats were steamed and kilned using a vegetable steamer (model VS-30; Salton, Dollard-des-Ormeaux, QC, Canada) and forced air convection lab oven (Isotemp model 838F, Fisher Scientific, Waltham, MA, USA), respectively. Groats were steamed at $100{ }^{\circ} \mathrm{C}$ to increase the groat moisture content to $18 \%$. Steamed groats were cooled for $30 \mathrm{~min}$ and then placed onto a perforated metal screen tray and exposed to hot air in the forced air oven for a $90 \mathrm{~min}$ killing process $\left(45 \mathrm{~min}\right.$ at $102{ }^{\circ} \mathrm{C}$, cooling from 102 to $83^{\circ} \mathrm{C}$ over 10 min, 10 min at $83^{\circ} \mathrm{C}$, cooling from 83 to $60^{\circ} \mathrm{C}$ over $25 \mathrm{~min}$ ). The moisture content of kilned oats was approximately $9 \%$.

Fractions produced from dehulling (groats, hulls, remainders) and the heat-treated groats were ground using the Retsch mill fitted with the $500 \mu \mathrm{m}$ sieve and analysed for mycotoxins and ergosterol using the LC-MS/MS and GC-MS methods described above. CUL was included in the analytical method for only 4 samples. The remaining analytes were monitored in the oat fractions from all 14 samples.

\section{Statistical analysis}

Statistical analyses were performed using SigmaPlot 13.0 (Systat, San Jose, CA, USA) and a level of significance at $P=0.05$.

\section{Results}

\section{Comparison of grinders for the comminution of whole oats}

The particle size distribution of oats ground using the different grinders and settings listed in Table 1 are shown in Figure 1. Over $50 \%$ of ground sample prepared using the Ditting commercial coffee grinder or Romer mill did not pass through the $1,180 \mu \mathrm{m}$ sieve of the box sifter. As expected, the 'coarse' grind produced less smaller particles than the 'fine' grind on the Ditting grinder. However, for the Romer mill there was no apparent difference in particle size distributions between the coarse and fine grind settings.

The Retsch and Perten mills produced a more desirable particle size distribution; that is, a larger proportion of the particles produced by these mills were smaller. The percentage of ground sample that was small enough to pass through the $1,180 \mu \mathrm{m}$ sieve of the box sifter ranged from $89 \%$ to $100 \%$ for these grinders. The majority of ground oats produced by these grinders was in fractions smaller than $475 \mu \mathrm{m}$.

There was also noticeable improvement in the particle size distribution as sieves with smaller opening sizes were used in the Retsch and Perten grinders. The biggest improvement 


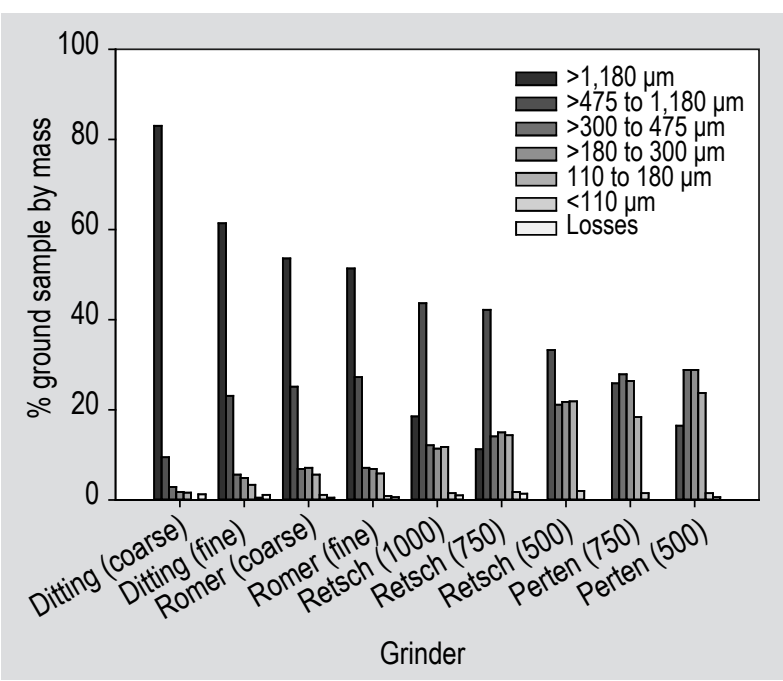

Figure 1. Particle size distribution obtained after grinding whole oats using various grinders and settings. Information in parentheses after each grinder brand indicates the setting or sieve opening size $(\mu \mathrm{m})$ used.

occurred with the Retsch mill with the $500 \mu \mathrm{m}$ as compared to the $750 \mu \mathrm{m}$ sieve. Material large enough that it couldn't pass through the $1,180 \mu \mathrm{m}$ sieve of the box sifter was eliminated and the material greater than $475 \mu \mathrm{m}$ in size was reduced from 42 to $33 \%$.

As with the Retsch, there was more ground oats as smaller particle sizes when the sieve on the Perten was changed from 750 to $500 \mu \mathrm{m}$. The amount of material that was not small enough to pass through the $475 \mu \mathrm{m}$ sieve decreased from 26 to $16 \%$.

Grinding of $1 \mathrm{~kg}$ of whole oats, plus cleaning the grinder to prepare for a subsequent sample, took over $30 \mathrm{~min}$ for the Romer and Perten grinders (Table 1). These grinders both heated up quickly while the oats were being ground. In order to prevent the sample from jamming the grinder, grinding was stopped at frequent intervals to allow the equipment to cool down. Since the capacity of the feeder on the Perten grinder was approximately $500 \mathrm{~g}$, the operator had to add multiple portions to the feeder to grind the entire $1 \mathrm{~kg}$. The whole oats had to also be assisted through the Perten feeder to facilitate movement into the grinder. The whole oats were pushed through the feeder with a metal spatula and the feeder was tapped to prevent blockage. Without this assistance the whole oats would remain in the hopper and would not fall into the grinder. In addition, ground oats were retained on the sieves of the Retsch grinder, but this material was easily accessible and could be removed by tapping the sieve into the ground sample collection container.

\section{Comparison of division methods for ground oats}

Results from the investigation into the ability of various methods to accurately and precisely divide ground oats is presented in Figure 2(A). Two sets of grinding conditions were selected from the comparison of grinders in order to cover ideal (Retsch grinder fitted with the $500 \mu \mathrm{m}$ sieve) and less ideal particle size fraction distributions (Ditting commercial coffee grinder on the coarsest setting). For the sample ground using the Ditting grinder, all four dividing methods produced test portions with consistent size fraction distributions. The mean, as well as the variance of the mean percent mass of each particle size fraction, was not significantly different amongst the six size fractions produced by the Ditting grinder (Welch's ANOVA assuming unequal variances; $P>0.05$ ).

However, the four dividing methods did not produce consistent size fraction distributions when the oats sample ground using the Retsch grinder was divided. The variance of the mean percent mass of particle size fractions significantly differed amongst the dividing methods. Significant differences in variances were observed for the 110 to $180 \mu \mathrm{m},>180$ to $300 \mu \mathrm{m}$, and $>475$ to $1,180 \mu \mathrm{m}$ particle size fractions. The variance from the scooping method was always amongst the highest. The rank order of variance from the other methods was not consistent.

In addition, there were differences amongst the size fraction distributions themselves. As illustrated in Figure 2(B), the differences amongst distributions are small. The differences occur due to lower amounts of the largest particles, and higher amounts of the medium particles, in the ground oats divided using the rotary sample divider. Over $68 \%$ of the sample divided using the rotary sample divider was 110 to $475 \mu \mathrm{m}$ in diameter, as compared to $63-65 \%$ of the samples divided using the other methods. Only $25 \%$ of the sample divided using the rotary sample divider was $>475 \mu \mathrm{m}$ in diameter, as compared to $28-31 \%$ of the samples divided using the other methods.

\section{Distribution of mycotoxins and ergosterol amongst particle size fractions}

Out of the 25 mycotoxin analytes in the testing method, only 11 were detected in at least one of the two fractionated oat samples. BEA, ENN B, and TTX were present in both samples. NIV was only in sample 1 , and OTA, DON, DON3G, ZEN, AOH, AME, and ENN A were only in sample 2. Ergosterol was present in both samples. The relative amounts of mycotoxins present in the two fractionated oat samples are displayed in Figure 3. For the detected mycotoxins, concentrations were set to half the limit of quantitation when one of the particle size fractions from a sample did not contain quantifiable concentrations. This occurred with NIV in the $<110 \mu \mathrm{m}$ fraction and ENN B 


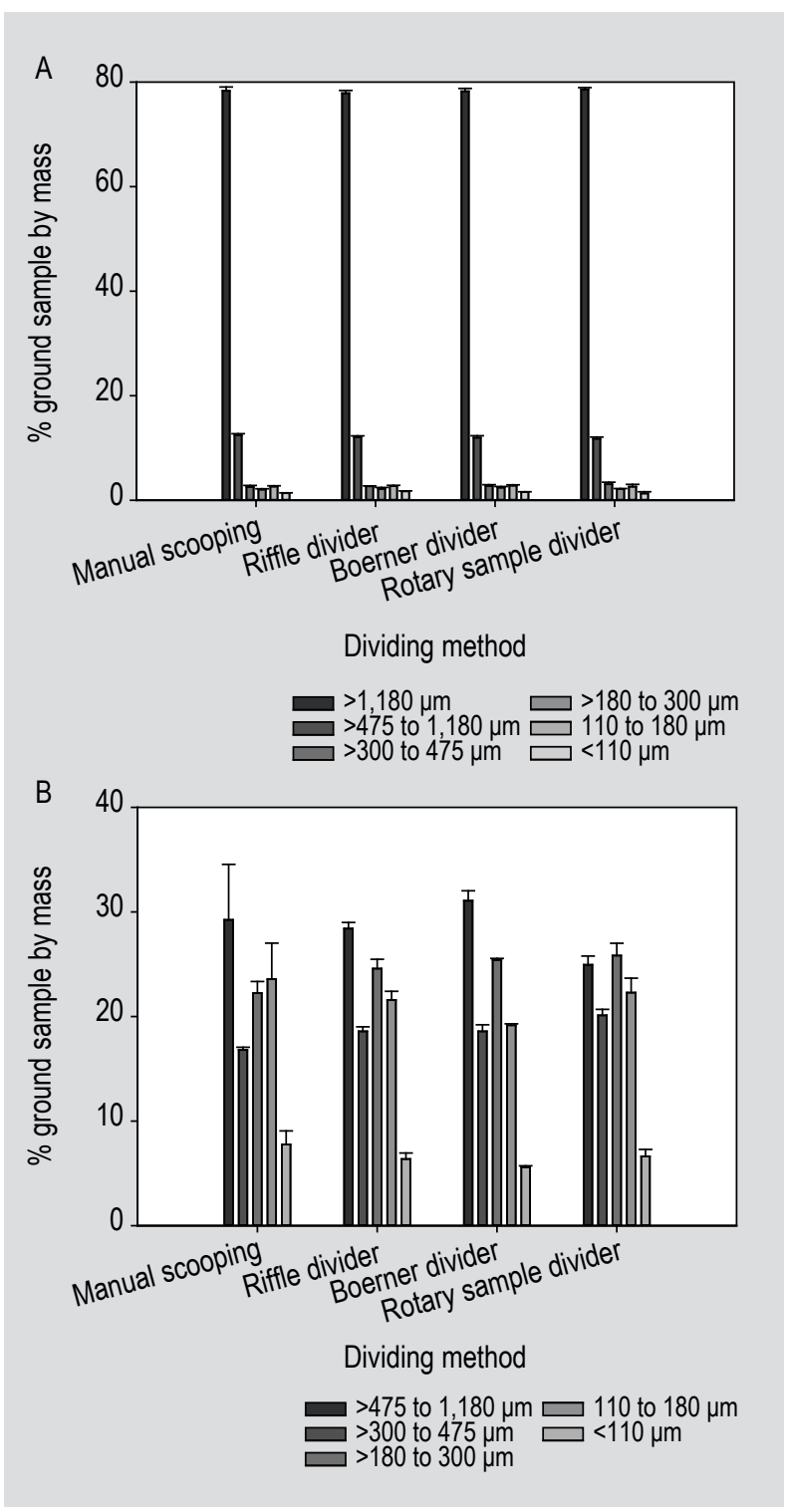

Figure 2. Uniformity of ground oats particle size distribution after division by different methods. Bars and whiskers indicate mean percentage \pm standard deviation of total sample mass $(n=3)$ of ground oats particle size fractions determined by box sifting. (A) Oats ground using the Ditting commercial coffee grinder on the 'coarse' setting. (B) Oats ground using the Retsch mill fitted with a $500 \mu \mathrm{m}$ sieve.

and DON-3G in the $>475 \mu \mathrm{m}$ fraction. In addition, ZEN and ENN A were not included in Figure 3 because they were only detected in the $>110$ to $180 \mu \mathrm{m}$ and $>180$ to $300 \mu \mathrm{m}$ fractions.

\section{Effect of dehulling oats on mycotoxin and ergosterol concentrations in oat fractions}

Table 2 summarises the concentrations of ergosterol and mycotoxin measured in the oat fractions produced by the dehulling process. Median concentrations were nominally higher in hulls as compared to groats for ergosterol and most

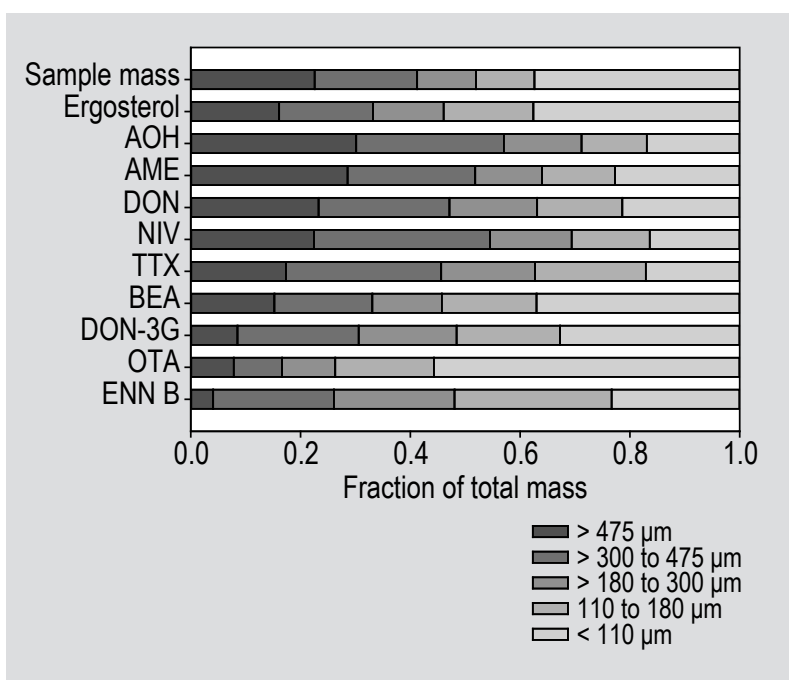

Figure 3. Distribution of mycotoxins and ergosterol amongst particle size fractions of ground oats. $A M E$ = alternariol methyl ether; $\mathrm{AOH}=$ alternariol; $\mathrm{BEA}=$ beauvericin; $\mathrm{DON}=$ deoxynivalenol; DON-3G = DON-3-glucoside; ENN B = enniatin $B$; NIV = nivalenol; OTA = ochratoxin A; TTX = tentoxin.

mycotoxins. The exceptions were BEA, ENN A1, AOH, and AME, where concentrations in the groats appeared to be higher than in the hulls.

ZEN, NIV, HT-2, and 3-ADON occurred infrequently and at low concentrations in the samples. These mycotoxins were only quantifiable in hulls, and were below the limit of quantification in groats for all samples.

Processing factors were estimated as the ratio of mycotoxin concentrations in groats or hulls to the concentration in whole oats, back-calculated from concentrations in oat fractions and the masses of the oat fractions. Calculations in whole oats were estimated in this manner as opposed to analysing a separate portion of whole oats in order to avoid variation due to the heterogeneity of mycotoxins that has been noted in whole oats (Whitaker et al., 2015a) and other cereal grains (Tittlemier et al., 2012).

For DON and OTA, the median ratios of groats to whole oats concentrations were 0.13 and 0.55 , respectively. These ratios reflected the decreases in concentration in groats as compared to whole oats. The median ratios of hulls to whole oats concentrations were higher, at 3.5 for DON and 3.2 for OTA.

Figure 4 illustrates the relative distribution of mycotoxin and ergosterol amongst dehulled oat fractions for selected analytes. While groats and hulls accounted for a median of 71 and $28 \%$ of the mass of dehulled whole oats, the majority of ergosterol and mycotoxin mass was associated with hulls. For the mycotoxins, medians of $48 \%$ (DON-3G) to $100 \%$ (HT-2 
Table 2. Concentrations of mycotoxins and ergosterol in oat processing fractions.

\begin{tabular}{|c|c|c|c|c|}
\hline Analyte $^{1}$ & Fraction & $\begin{array}{l}\text { Samples } \\
>\text { LOQ }^{2}(\%)\end{array}$ & $\begin{array}{l}\text { Median } \\
(\mu \mathrm{g} / \mathrm{kg})\end{array}$ & $\begin{array}{l}\text { Range } \\
(\mu \mathrm{g} / \mathrm{kg})\end{array}$ \\
\hline \multirow[t]{3}{*}{ ergosterol } & groats & 100 & 640 & $61-1,870$ \\
\hline & hulls & & 3,640 & $546-19,800$ \\
\hline & remainders ${ }^{3}$ & & 5,550 & $5,380-9,330$ \\
\hline \multirow[t]{3}{*}{ CUL } & groats & 100 & 31 & $12-50$ \\
\hline & hulls & & 224 & 135-397 \\
\hline & remainders & & 162 & $86-420$ \\
\hline \multirow[t]{3}{*}{ DON } & groats & 93 & 214 & $<30-600$ \\
\hline & hulls & & 856 & $<30-7,859$ \\
\hline & remainders & & 2,699 & $<30-7,847$ \\
\hline \multirow[t]{3}{*}{ TTX } & groats & 93 & 19 & $<5-139$ \\
\hline & hulls & & 49 & $<5-160$ \\
\hline & remainders & & 25 & $<5-122$ \\
\hline \multirow[t]{3}{*}{ BEA } & groats & 93 & 60 & $<2-83$ \\
\hline & hulls & & 28 & $2.6-71$ \\
\hline & remainders & & 9.1 & $<2-104$ \\
\hline \multirow[t]{3}{*}{ ENN B } & groats & 71 & 33 & $<16-40$ \\
\hline & hulls & & 107 & $<16-259$ \\
\hline & remainders & & 43 & $<16-289$ \\
\hline \multirow[t]{3}{*}{ DON-3G } & groats & 71 & 179 & $<50-252$ \\
\hline & hulls & & 244 & $<50-555$ \\
\hline & remainders & & 259 & $<50-841$ \\
\hline \multirow[t]{3}{*}{$\mathrm{AOH}$} & groats & 71 & 28 & $<4-50$ \\
\hline & hulls & & 25 & $<4-305$ \\
\hline & remainders & & 37 & $<4-53$ \\
\hline \multirow[t]{3}{*}{ AME } & groats & 57 & 32 & $<4-32$ \\
\hline & hulls & & 14 & $<4-124$ \\
\hline & remainders & & 19 & $<4-32$ \\
\hline \multirow[t]{3}{*}{ ENN A1 } & groats & 50 & 11 & $<5-11$ \\
\hline & hulls & & 8.2 & $<5-17$ \\
\hline & remainders & & 11 & $<5-12$ \\
\hline
\end{tabular}

\begin{tabular}{|c|c|c|c|c|}
\hline Analyte $^{1}$ & Fraction & $\begin{array}{l}\text { Samples } \\
>\mathrm{LOQ}^{2}(\%)\end{array}$ & $\begin{array}{l}\text { Median } \\
(\mu \mathrm{g} / \mathrm{kg})\end{array}$ & $\begin{array}{l}\text { Range } \\
(\mu \mathrm{g} / \mathrm{kg})\end{array}$ \\
\hline \multirow[t]{3}{*}{ ENN B1 } & groats & 43 & 24 & $<16-24$ \\
\hline & hulls & & 27 & $<16-79$ \\
\hline & remainders & & 50 & $<16-70$ \\
\hline \multirow[t]{3}{*}{ ZEN } & groats & 43 & $<20$ & $\mathrm{a}^{\mathrm{a}}$ \\
\hline & hulls & & 55 & $<20-85$ \\
\hline & remainders & & 37 & $<20-43$ \\
\hline \multirow[t]{3}{*}{ OTA } & groats & 29 & 3.6 & $<0.6-5.2$ \\
\hline & hulls & & 7.3 & $<0.6-16$ \\
\hline & remainders & & $<0.6$ & - \\
\hline \multirow[t]{3}{*}{ NIV } & groats & 29 & $<60$ & - \\
\hline & hulls & & 77 & $<60-167$ \\
\hline & remainders & & 76 & $<60-76$ \\
\hline \multirow[t]{3}{*}{ ENN A } & groats & 21 & 7.8 & $<2-7.8$ \\
\hline & hulls & & 8.7 & $<2-14$ \\
\hline & remainders & & 2.2 & $<2-5.3$ \\
\hline \multirow[t]{3}{*}{ HT-2 } & groats & 21 & $<60$ & - \\
\hline & hulls & & 70 & $<60-137$ \\
\hline & remainders & & $<60$ & - \\
\hline \multirow[t]{3}{*}{ 3-ADON } & groats & 14 & $<50$ & - \\
\hline & hulls & & 182 & $<50-264$ \\
\hline & remainders & & $<50$ & - \\
\hline \multicolumn{5}{|c|}{$\begin{array}{l}{ }^{1} \text { AME = alternariol methyl ether; } \mathrm{AOH}=\text { alternariol; } \mathrm{BEA}=\text { beauvericin; } \\
\mathrm{CUL}=\text { culmorin; } \mathrm{DON}=\text { deoxynivalenol; 3-ADON = 3-acetyldeoxynivalenol; } \\
\text { DON-3G = DON-3-glucoside; ENN A = enniatin A; ENN A1 = enniatin } \\
\text { A1; ENN B = enniatin B; ENN B1 = enniatin B1; HT-2 = HT-2 toxin; NIV } \\
=\text { nivalenol; OTA = ochratoxin A; TTX = tentoxin; ZEN = zearalenone. } \\
{ }^{2} \text { LOQ = limit of quantification. } \\
{ }^{3} \text { Remaining oat kernels not dehulled by laboratory-scale huller. }\end{array}$} \\
\hline
\end{tabular}

toxin and 3-ADON) of mass was associated with hulls; $67 \%$ of the mass of ergosterol was associated with hulls.

\section{Effect of heat treatment on mycotoxin and ergosterol concentrations in groats}

Changes in concentration of ergosterol and selected mycotoxins after steaming and kilning of groats are shown in Figure 5. Ergosterol concentrations were consistently higher in steamed and kilned groats as compared to the untreated groats. Absolute concentration increases ranged from 0.86 to $1.21 \mathrm{mg} / \mathrm{kg}$ in the 14 samples analysed. On the other hand, DON and DON-3G concentrations were consistently lower in steamed and kilned as opposed to untreated groats. Decreases in concentration were observed in 6 of the 7 occurrences of DON (mean decrease of 27\%) and 4 out of the 6 occurrences of DON-3G (mean decrease of 20\%) in the samples after steaming and kilning. There were no consistent changes in TTX concentrations after

steaming and kilning. There were too few occurrences of quantifiable concentrations of the other mycotoxins to determine if changes were due to heat treatment or sample heterogeneity.

\section{Discussion}

\section{Comparison of grinders for the comminution of whole oats}

The rotor beater type grinders (Retsch and Perten) produced more of the smaller particles than the burr mill type grinders (coffee grinders and Romer mill), and therefore produced more desirable particle size distributions. In general, more smaller particles are preferred after comminution as this will decrease the heterogeneity of mycotoxins in a sample and the variation due to sampling (Smith, 2001). The burr type mills evaluated have limited options for adjusting particle sizes produced, as adjustments are done by modifying the space between the rotating abrasive surfaces. The rotor 


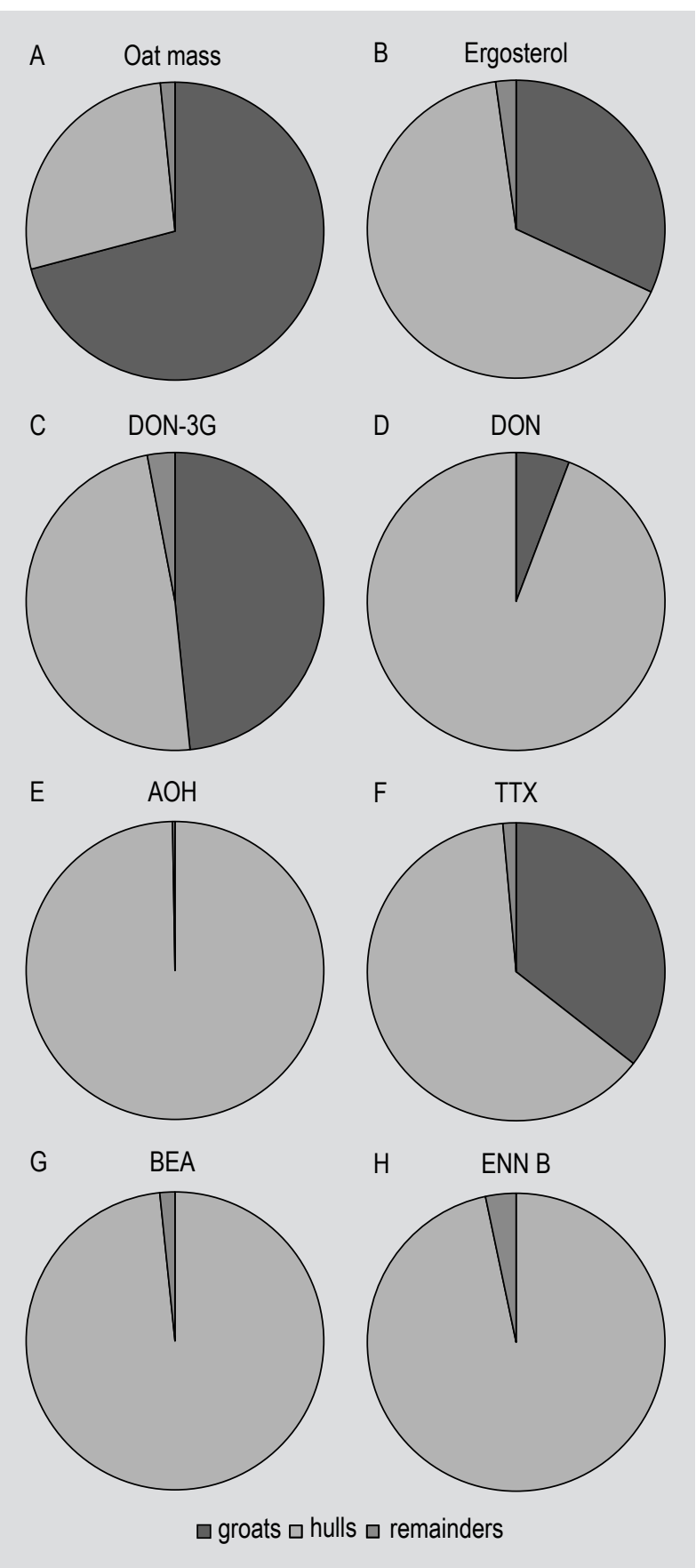

Figure 4. Median percentage of mycotoxin and ergosterol mass distributed amongst dehulled oat fractions. (A) Oat mass; (B) ergosterol; (C) deoxynivalenol-3-glucoside; (D) deoxynivalenol; $(E)$ alternariol; $(F)$ tentoxin; (G) beauvericin; $(H)$ enniatin $B$.

beater type grinders use sieves of various opening sizes to adjust the particle size distribution of ground grain.

Oat hulls were more difficult to comminute than endosperm of the kernels. Visually, it could also be seen that for the burr mill type grinders, the larger particle sizes tended to be oat hulls. The shearing action of this type of grinder produced large slivers of hulls amongst the smaller endosperm particles.
We chose to use the Retsch fitted with the $500 \mu \mathrm{m}$ sieve for processing of oat samples for subsequent mycotoxin and ergosterol analyses for two main reasons. First, this equipment produced a desirable particle size distribution. Approximately $67 \%$ of ground oats comminuted in this system were small enough to pass through the $475 \mu \mathrm{m}$ sieve on the box sifter. Fragments of hulls were still visible in the ground oats, but they were smaller than the hull fragments produced by the other grinders. Secondly, the time to grind $1 \mathrm{~kg}$ of whole oats and clean the grinder in preparation for the next sample was only $6 \mathrm{~min}$. The chosen grinder system provided a good balance between maximising the amount of desirable particle sizes and minimising the time needed to comminute sample and clean the grinder.

\section{Comparison of division methods for ground oats}

All of the rotary and gravity fed stationary dividers assessed in this study outperformed the manual scooping method for dividing ground oats. Manual scooping was the method the least able to maintain a consistent particle size distribution amongst replicate test portions taken from the same finely ground material. When subsampling the coarsely ground oats (in which over $90 \%$ of the material had a diameter larger than $475 \mu \mathrm{m}$ ), all division methods performed the same.

There was indication of bias in the particle size distributions amongst the division methods for finely ground oats. No bias was apparent during the division of the coarsely ground oats. However, the least biased division method could not be determined without knowing the 'true' distribution. Even though the division method appeared to affect the particle size distribution, as well as the variance of the distribution for replicate test portions, the choice of division may not have practical effects on the analysis of mycotoxins in ground oats. Using the results from this work, perturbations in the particle size distribution due to bias and/or variance from the sample division method would cause only a small change in mycotoxin concentration in a sample of ground oats.

The particle size distributions from the manual scooping and rotary sample divider methods (Figure 2B) were considered along with the distribution of OTA and DON in the particle size fractions as shown in Figure 3. Assuming the concentrations of OTA and DON are constant within a particle size fraction, the estimated concentrations of OTA (1.79 vs $1.77 \mu \mathrm{g} / \mathrm{kg}$ ) and DON (752 vs $769 \mu \mathrm{g} / \mathrm{kg})$ in the manual scooping and rotary sample divided test portions only vary up to $2 \%$. This small difference would be obscured by the variability due to the analytical test method, which has been reported at a relative standard deviation of 7-9\% for OTA (Whitaker et al., 2015a,b) and 22\% for DON at similar concentrations (Whitaker et al., 2000).

The impact of a method for the division of ground oats is minimal in this work, but analysts should separately 

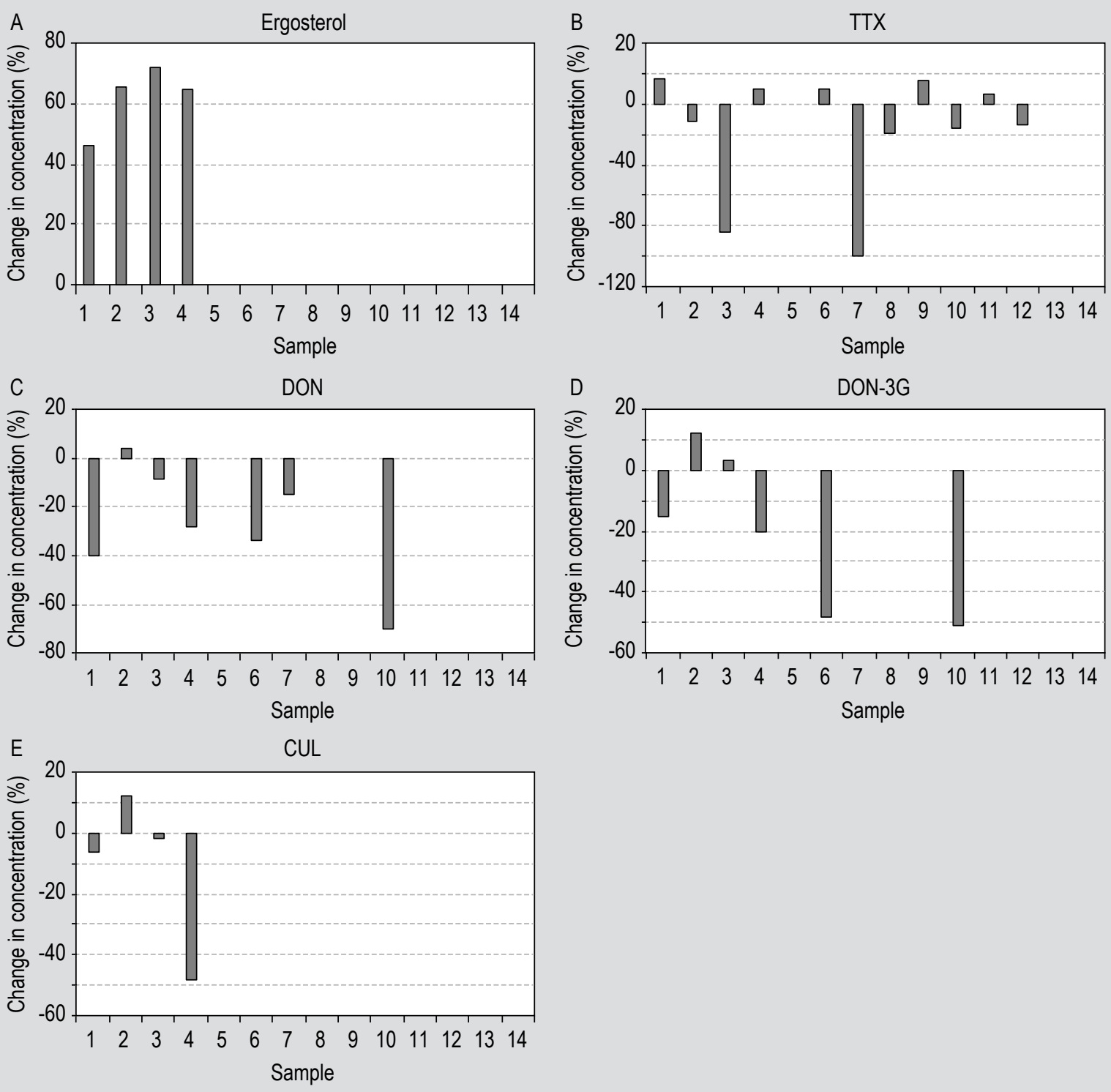

Figure 5. Change in ergosterol and mycotoxin concentration after steaming and kilning groats. The percent change was calculated as the difference in concentrations between untreated and heat-treated groats, divided by the concentration in untreated groats. (A) ergosterol; (B) tentoxin; (C) deoxynivalenol; (D) deoxynivalenol-3-glucoside; (E) culmorin. Instances of no bars in (B-D) indicate that analyte was not detected in untreated groats. Only samples 1 through 4 were analysed for ergosterol and culmorin.

estimate or assess the impact for their own work situations. The greater the differences in mycotoxin concentration amongst the particle size fractions, the greater will be the impact of variations in particle size distributions on measured mycotoxin concentrations.

\section{Distribution of mycotoxins and ergosterol amongst particle size fractions}

The aim of this experiment was not to determine where the mycotoxins were located within oat kernels, but to investigate the relationship to particle size in order to gauge if and how grinding and dividing processes may affect mycotoxin analysis if particle size distribution changes during sub-sampling. If mycotoxins and ergosterol were evenly distributed amongst the particle size fractions, the analyte distributions would mirror the sample mass distribution bar in Figure 3. Deviations of analyte distribution from the sample mass distribution indicate otherwise. These differences in analyte distribution amongst particle size fractions could reflect that there is a gradient of analytes within kernels. The differences could also reflect differences in extractability from different particle sizes. This has been observed before (Garcia-Fonseca et al., 2010; Schatzki and Toyofuku, 2003; Tittlemier et al., 2012). 
The only compound where a majority (>50\%) of total mycotoxin mass was in one particle size fraction was OTA. Other analytes were distributed more amongst all of the particle size fractions. A similar presence of the majority of OTA in the smallest particle size fraction has been observed for wheat (Tittlemier et al., 2012).

The results from this experiment suggest that the analysis of OTA may be more sensitive towards the methods of sample preparation that could affect the presence of particles $<110 \mu \mathrm{m}$ in diameter than other mycotoxins. Comminution, as well as processes involved with handling and/or subsampling, can all affect the proportion of smallest particles present and therefore should be assessed to avoid biasing particle size fraction distributions of samples and subsamples.

\section{Effect of dehulling oats on mycotoxin and ergosterol concentrations in oat fractions}

This study contains the first reports of the fate of OTA, CUL, ZEN, AOH, AME, TTX, ENNs and BEA in oats, and showed that the majority of ergosterol and mycotoxins is associated with hulls. Quantifying the magnitude of the effect of processing was limited, because of the low frequency of occurrence and low concentrations of these mycotoxins in the naturally infected samples used in this study. However, the predominance of mycotoxins in oat hulls with a much lower presence, or even absence, in groats was consistent for the quantifiable analytes.

The large decrease in DON, HT-2, and NIV concentrations in groats due to dehulling observed in this study was consistent with past research. For example, reductions on the order of 88 to $94 \%$ were reported for DON (Ivanova et al., 2016; Scudamore et al., 2007). The median reduction in the current study was $87 \%$. HT-2 and NIV were also reduced to a similar extent in other studies (Adler et al., 2003; Ivanova et al., 2016; Scudamore et al., 2007). In the current study, HT-2 and NIV were only detected in the hull fraction. None of the groats analysed contained quantifiable amounts. Concentrations of ergosterol in groats were approximately half those in whole oats, which was also consistent with previous research. The median ratio of 0.47 for ergosterol concentration in groats to whole oats was very similar to the ratio of 0.50 observed by Adler et al. (2003).

These results suggest fungi have limited potential to penetrate the hulls and colonise the endosperm or the germ. Ivanova et al. (2016) reported that fungal DNA was concentrated in oat fractions representing hulls and bran and outer layers of endosperm, which is in line with the mycotoxin distributions observed in the current study. The current results also imply that most mycotoxins are not readily translocated from hulls to oat kernel.
Notably though, DON-3G and TTX tended towards higher occurrence in groats than the other analytes. A shift in occurrence of DON-3G towards groats was noted by Ivanova et al. (2016) as well, and raises questions regarding if there are specific areas on or within an oat kernel of higher activity for transforming DON to DON-3G. TTX has not been previously reported in oat fractions.

While dehulling in the production of oat-containing foods would have a beneficial effect of minimising consumers' exposure, there are potentially problematic implications for the use of oat hulls in feed. Some of the whole oats used in the dehulling experiment generated hulls containing DON at concentrations higher than the proposed Canadian guideline of $5 \mathrm{mg} / \mathrm{kg}$ for DON in cereals and cereal byproduct single ingredient feeds for calves, lactating dairy animals, and swine (Canadian Food Inspection Agency, 2017). It would be prudent to monitor oat hulls to ensure compliance with feed guidelines and to avoid harmful effects on livestock.

The association of mycotoxins with hulls could also impact exposure assessments and regulations. While oat hulls are used in animal feed, they are not used in food. One of the first steps in processing oats for use in food is dehulling, therefore accurate measures of consumers' exposure to mycotoxins via oat consumption should be based on concentrations in groats and not whole oats. Basing exposure assessments on the consumption of whole oats will overestimate exposure. The degree of overestimation would vary according to the mycotoxin considered. Based on the results of this study, exposure to DON and OTA could be overestimated by factors of $8 \times$ and $2 \times$, respectively if whole oat concentrations were considered as opposed to concentrations in groats.

\section{Effect of heat treatment on mycotoxin and ergosterol concentrations in groats}

Heat treatment of groats appeared to increase the fungal biomass, as ergosterol concentrations were consistently higher in oats that were steamed and kilned as compared to untreated groats. However, no increases in mycotoxin concentration were observed, suggesting the increase in fungal biomass was for non-toxigenic species, or that conditions were not conducive to mycotoxin production.

Changes in TTX concentrations for the 11 samples that contained quantifiable concentrations were not consistent; 5 samples showed increased concentrations in the heattreated groats, whereas 6 samples showed decreased concentrations. Combined with the low concentrations, this suggests the variation in concentrations observed were due to sample heterogeneity with respect to TTX. 
In addition, decreases in DON and DON-3G concentrations were observed. The consistency of the lower concentrations in the heat-treated groats suggests that the apparent differences were not simply sampling artefacts, as hypothesised for TTX. Reductions in DON content have been reported for wheat treated with super-heated steam for short periods of time (Cenkowski et al., 2007). Reductions of up to $52 \%$, observed at a temperature of $185^{\circ} \mathrm{C}$ for $2-6 \mathrm{~s}$, were attributed to thermal degradation. Smaller reductions in DON content observed at lower temperatures of $135^{\circ} \mathrm{C}$ and $110^{\circ} \mathrm{C}$ treated for 3-10 s were hypothesised to be due to a 'washing effect'. In the current study, steaming occurred at $100^{\circ} \mathrm{C}$ following by kilning at $102^{\circ} \mathrm{C}$ for $45 \mathrm{~min}$, suggesting that the prolonged exposure to heat and steam reduced DON and DON-3G content of groats.

\section{Conclusions}

Some of the steps involved in processing whole oats for analysis, and for processing for food and feed use did have an effect on mycotoxin concentrations. With respect to processing for analysis, the type of grinder and settings used to comminute whole oats affected the particle size distribution of ground sample. Rotor beater type grinders produced the more desirable finer ground samples as compared to burr type mills. When sub-dividing ground sample, the type of division method used is not expected to have a practical effect on mycotoxin analysis. With respect to processing oats for use, dehulling removed the majority of ergosterol and mycotoxins whereas heat treatment of groats increased fungal load but decreased the presence of some mycotoxins. These effects should be taken into account by analysts preparing whole oats for mycotoxin analysis, as well as regulators assessing dietary exposure and potential risk from the consumption of food and feed.

\section{Acknowledgements}

This work was a collaborative venture with funding contributed by the Canadian Grain Commission, the Prairie Oat Growers Association, the Saskatchewan Ministry of Agriculture, and the Canada-Saskatchewan Growing Forward 2 bi-lateral agreement.

\section{Conflict of interest}

The authors declare no conflict of interest.

\section{References}

Adler, A., Lew, H., Moudry, J., Sterba, Z., Vratilova, K., Edinger, W., Brodacz, W. and Kiendler, E., 2003. Microbiological and mycotoxicological quality parameters of naked and covered oats with regard to the production of bran and flakes. Die Bodenkultur 54: 41-49.
Bouphasiri, C. and Verchomin, S., 2005. A case study of the Canadian oat market: the evolution from the central desk system to the open market. Alberta Agriculture, Food and Rural Development, Edmonton, Canada.

Campbell, H., Choo, T.M., Vigier, B. and Underhill, L., 2002. Comparison of mycotoxin profiles among cereal samples from eastern Canada. Canadian Journal of Botany 80: 526-532. https:// doi.org/10.1139/b02-055

Cenkowski, S., Pronyk, C., Zmidzinska, D. and Muir, W.E., 2007. Decontamination of food products with superheated steam. Journal of Food Engineering 83: 68-75. https://doi.org/10.1016/j. jfoodeng.2006.12.002

Canadian Food Inspection Agency, 2017. Proposal - contaminant standards for aflatoxins, deoxynivalenol, fumonisins, ergot alkaloids and Salmonella in livestock feeds. Available at: https://tinyurl. com/rpsby8z

Chen, W., Turkington, T.K., Lévesque, C.A., Bamforth, J.M., Patrick, S.K., Lewis, C.T., Chapados, J.T., Gaba, D., Tittlemier, S.A., MacLeod, A. and Gräfenhan, T., 2016. Geography and agronomical practices drive diversification of the epiphytic mycoflora associated with barley and its malt end product in western Canada. Agriculture, Ecosystems and Environment 226: 43-55. https://doi.org/10.1016/j. agee.2016.03.030

Clear, R.M., Patrick, S.K. and Gaba, D., 2000. Prevalence of fungi and fusariotoxins on oat seed from western Canada, 1995-1997. Canadian Journal of Plant Pathology 22: 310-314. https://doi. org/10.1080/07060660009500480

Garcia-Fonseca, S., Ballesteros-Gomez, A., Rubio, S. and PerezBendito, D., 2010. Supramolecular solvent-based microextraction of ochratoxin A in raw wheat prior to liquid chromatographyfluorescence determination. Journal of Chromatography A 1217: 2376-2382. https://doi.org/10.1016/j.talanta.2015.11.014

Grusie, T., Cowan, V., Singh, J., McKinnon, J. and Blakley, B., 2017. Correlation and variability between weighing, counting and analytical methods to determine ergot (Claviceps purpurea) contamination of grain. World Mycotoxin Journal 10: 209-218. https://doi.org/10.3920/WMJ2016.2174

Ivanova, L., Sahlstrøm, S., Rud, I., Uhlig, S., Fæste, C.K., Eriksen, G.S. and Divon, H.H., 2016. Effect of primary processing on the distribution of free and modified Fusarium mycotoxins in naturally contaminated oats. World Mycotoxin Journal 10: 73-88. https://doi. org/10.3920/WMJ2016.2092

Kuchenbuch, H.S., Becker, S., Schulz, M., Cramer, B. and Humpf, H.U., 2018. Thermal stability of T-2 and HT-2 toxins during biscuitand crunchy muesli-making and roasting. Food Additives and Contaminants Part A 35: 2158-2167. https://doi.org/10.1080/19 440049.2018.1530456

Lee, H.J., Dahal, S., Perez, E.G. Kowalski, R.J., Ganjyal, G.M. and Ryu, D., 2017. Reduction of ochratoxin A in oat flakes by twin-screw extrusion processing. Journal of Food Protection 80: 1628-1634. https://doi.org/10.4315/0362-028X.JFP-16-559

Martos, P.A., Thompson, W. and Diaz, G.J., 2010. Multiresidue mycotoxin analysis in wheat, barley, oats, rye and maize grain by high performance liquid chromatography-tandem mass spectrometry. World Mycotoxin Journal 3: 205-223. https://doi. org/10.3920/WMJ2010.1212 
Schatzki, T.F. and Toyofuku, N., 2003. Sample preparation and presampling of pistachios. Journal of Agricultural and Food Chemistry 51: 6068-6072. https://doi.org/10.1021/jf0301955

Schmidt, H.S., Becker, S., Cramer, B. and Humpf, H.-U., 2017. Impact of mechanical and thermal energies on the degradation of $\mathrm{T}-2$ and HT-2 toxins during extrusion cooking of oat flour. Journal of Agricultural and Food Chemistry 65: 4177-4183. https://doi. org/10.1021/acs.jafc.7b01484

Scudamore, K.A., Baillie, H., Patel, S. and Edwards, S.G., 2007. Occurrence and fate of Fusarium mycotoxins during commercial processing of oats in the UK. Food Additives and Contaminants 24: 1374-1385. https://doi.org/10.1080/02652030701509972

Seitz, L.M., Mohr, H.E., Burroughs, R. and Sauer, D.B., 1977. Ergosterol as an indicator of fungal invasion in grains. Cereal Chemistry 54: 1207-1217.

Smith, P.L., 2001. A primer for sampling solids, liquids, and gases. American Statistical Association and the Society for Industrial and Applied Mathematics, Philadelphia, PA, USA.

Tamburic-Ilincic, L., 2010. Fusarium species and mycotoxins associated with oat in southwestern Ontario, Canada. Canadian Journal of Plant Science 90: 211-216. https://doi.org/10.4141/cjps09139

Tittlemier, S.A., Blagden, R., Chan, J., Gaba, D., McKendry, T., Pleskach, K. and Roscoe, M., 2019. Fusarium and Alternaria mycotoxins in Canadian wheat and durum harvest samples. Canadian Journal of Plant Pathology 41: 403-414. https://doi.org/10.1080/0706066 1.2019 .1592784
Tittlemier, S.A., Blagden, R., Chan, J., Roscoe, M. and Pleskach, K., 2020. A multi-year survey of mycotoxins and ergosterol in Canadian oats. Mycotoxin Research 36: 103-114. https://doi.org/10.1007/ s12550-019-00373-9

Tittlemier, S.A., Roscoe, M., Kobialka, C. and Blagden, R., 2012. Considerations in the preparation of laboratory samples for the analysis of ochratoxin A in wheat. World Mycotoxin Journal 5: 107-116. https://doi.org/10.3920/WMJ2012.1393

Tittlemier, S.A., Varga, E., Scott, P.M. and Krska, R., 2011. Sampling of cereals and cereal-based foods for the determination of ochratoxin A: an overview. Food Additives and Contaminants Part A 28: 775785. https://doi.org/10.1080/19440049.2011.559278

Whitaker, T.B., Hagler Jr., W.M., Giesbrecht, F.G. and Johansson, A.S., 2000. Sampling, sample preparation, and analytical variability associated with testing wheat for deoxynivalenol. Journal of AOAC International 83: 1285-1292.

Whitaker, T.B., Slate, A.B., Nowicki, T. and Giesbrecht, F.G., 2015a. Variability and distribution among sample test results when sampling unprocessed oat lots for ochratoxin A. World Mycotoxin Journal 8: 511-524. https://doi.org/10.3920/WMJ2014.1858

Whitaker, T.B., Slate, A.B., Nowicki, T.W. and Giesbrecht, F.G., $2015 \mathrm{~b}$. Variability and distribution among sample test results when sampling unprocessed wheat lots for ochratoxin A. World Mycotoxin Journal 9: 163-178. https://doi.org/10.3920/WMJ2015.1970

Yan, W., Pageau, D., Martin, R., Cummiskey, A. and Blackwell, B., 2017. Is deoxynivalenol contamination a serious problem for oat in eastern Canada? Crop Science 57: 88-98. https://doi.org/10.2135/ cropsci2016.04.0263 